\title{
Polymorphisms in Fas Gene Is Associated with HIV-Related Lipoatrophy in Thai Patients
}

\author{
Sirirat Likanonsakul,, Tippawan Rattanatham, , Siriluk Feangvad, Sumonmal Uttayamakul, \\ Wisit Prasithsirikul, Somkid Srisopha, Ravee Nitiyanontakij,. Pimrapat Tengtrakulcharoen, ${ }^{1}$ \\ Maciej Tarkowski, ${ }^{3}$ Agostino Riva, ${ }^{3}$ Emi E. Nakayama, ${ }^{4}$ and Tatsuo Shioda ${ }^{4}$
}

\begin{abstract}
The present study aimed to evaluate the role of genetic polymorphisms in the emergence of lipoatrophy or lipodystrophy in HIV-infected patients with antiretroviral therapy (ART) in Thailand. Position 455 upstream of the Apolipoprotein C3 gene (ApoC3 T-455C, rs2854116), codon 64 of the Beta3 adrenergic receptor gene (AR $\beta 3$ Tcod64C, rs4994), and position 670 upstream of the Fas gene (Fas A-670G, rs1800682) were genotyped in 829 HIV-infected Thai patients who had started ART. Crude and adjusted incidence rate ratios (IRR) were calculated using Poisson regression. The serum levels of cholesterol, triglycerides, high-density lipoprotein (HDL), and low-density lipoprotein (LDL) were also analyzed. Multivariate analysis revealed an association between the Fas -670AA genotype, but not the ApoC 3 - 455 or $A R \beta 3$ cod64 genotypes, with the incidence of lipoatrophy after adjusting for gender and stavudine (d4T)-containing regimens (IRR $=1.72,95 \% \mathrm{CI}=1.20-2.45, p=0.003$ ). However, ApoC3 -455C homozygous patients showed elevated serum levels of triglycerides, while this genotype did not affect serum total cholesterol, HDL, or LDL levels in patients with lipoatrophy or lipodystrophy. In contrast, the $A R \beta 3$ cod64 genotype did not show any significant association with the serum levels of cholesterol, triglycerides, HDL, or LDL. In conclusion, Fas - 670AA affected the incidence of lipoatrophy in HIV-1infected Thai patients, while the ApoC3 - 455C allele affected the serum levels of triglycerides. These results confirmed the role of genetics in the development of ART-related metabolic disorders.
\end{abstract}

\section{Introduction}

$\mathbf{M}$ ETABOLIC AND MORPHOLOGICAL alterations observed in human immunodeficiency virus (HIV)-infected patients represent a significant health problem related both to the possible long-term consequences and to the behavioral and psychological well-being of patients. Since the introduction of highly active antiretroviral therapy (HAART), the life expectancy of patients infected with HIV type 1 (HIV-1) has increased remarkably. Despite the clinical benefits, longterm HAART is associated with a complex spectrum of morphological alterations, characterized by body changes that may stigmatize patients and compromise their compliance with therapy, as well as metabolic effects, including dyslipidemia and insulin resistance, which lead to an elevated risk of developing diabetes mellitus and myocardial infarction. ${ }^{1-3}$
Morphological alterations are collectively named lipodystrophy (LD); however, in recent years it has been recognized that fat loss and fat gain represent distinct entities. Clinical features of fat loss include loss of subcutaneous fat in the face, arms, legs, and buttocks, while fat accumulation is characterized by excess fat deposition in visceral adipose tissue in the abdomen, breasts, dorsocervical region, and trunk. $^{4}$

The underlying mechanism of antiretroviral therapy (ART)-related lipoatrophy (LA) has not been fully elucidated. Many mechanisms have been suggested, including mitochondrial toxicity by nucleoside reverse transcriptase inhibitors (NRTIs), inhibition of adipocyte differentiation by protease inhibitors (PIs), increased levels of inflammatory cytokines, and HIV itself. $^{5-7}$ Mitochondrial toxicity has been clearly shown to play a pivotal role; in particular, thymidine analogs are strong inhibitors of DNA polymerase- $\gamma$ and lead

\footnotetext{
${ }^{1}$ Bamrasnaradura Infectious Diseases Institute, Department of Disease Control, Ministry of Public Health, Nonthaburi, Thailand

${ }^{2}$ Faculty of Medicine Siriraj Hospital, Mahidol University, Bangkok, Thailand.

${ }^{3}$ Luigi Sacco Hospital, University of Milan, Milan, Italy.

${ }^{4}$ Research Institute for Microbial Diseases, Osaka University, Osaka, Japan.
} 
to mitochondrial depletion and dysfunction ${ }^{8}$; mainly stavudine $(\mathrm{d} 4 \mathrm{~T})$, but also zidovudine (AZT) and didanosine (ddI) are strongly related to LA. ${ }^{9,10}$ In previous in vitro and clinical studies, newer nucleoside and nucleotide agents, such as lamivudine (3TC), emtricitabine, abacavir, and tenofovir, appear to be much weaker inhibitors of mitochondrial DNA polymerase- $\gamma$ or other mitochondrial functions, and appear to be associated with a lower risk of events thought to be related to mitochondrial toxicity. ${ }^{11}$ However, a certain degree of mitochondrial toxicity is still present and will probably still affect HIV patients under ART, although to a lesser extent. ${ }^{12-14}$ In fact, switch studies from $\mathrm{d} 4 \mathrm{~T}$ to other NRTIs and complete switch off of thymidine analogs showed modest even if consistent increases in limb fat. ${ }^{15-17}$

The pathogenesis of lipohypertrophy appears to be multifactorial, with age, sex, HIV itself, immune depression, and duration and type of ART related to its appearance. ${ }^{18-20}$ PIs were suggested to be involved in lipohypertrophy; however, visceral fat accumulation also occurs in the absence of PIs. ${ }^{21,22}$ A compartment-specific effect of mitochondrial toxicity within the adipose tissue may be related to lipohypertrophy ${ }^{23}$ as well as dysregulation of fatty acid metabolism and altered expression of adipokines. ${ }^{24-26}$

However, LA and lipohypertrophy do not occur in all treated patients, and there is a very large degree of interindividual variability in the timing of emergence and severity of symptoms. A study of identical twins showed that genetic factors are involved in the accumulation of visceral adipose tissue. ${ }^{27}$ These data suggest that host genetic factors may play a role, and inherited predispositions may have a significant influence on the appearance of LD and metabolic alterations as well as on the viroimmunological response to the drugs.

Therefore, host genetic polymorphisms may have a significant effect on the response to ART in terms of metabolism and immune response. ${ }^{28}$ A study of Italian HIV patients suggested that single nucleotide polymorphisms (SNPs) in genes involved in apoptosis and lipid metabolism mediate the development of LA. ${ }^{29}$ In particular, the TT and CT genotypes at position - 455 of the Apolipoprotein C3 (ApoC3) gene (ApoC3 $\mathrm{T}-455 \mathrm{C}$, rs2854116), nonsynonymous (W to $\mathrm{R}) \mathrm{CC}$ and $\mathrm{CT}$ genotypes at codon 64 of the Beta3 adrenergic receptor (AR $\beta 3$ ) gene (AR $\beta 3$ Tcod64C, rs4994), and the AA genotype at position -670 of the Fas gene (Fas A-670G, rs1800682) were associated with increased incidence rates of LA. ${ }^{29}$ ApoC3 protein, localized mainly in very low-density lipoprotein and high-density lipoprotein (HDL), is involved in fat metabolism and may delay the catabolism of triglyceride-rich particles. ApoC3 inhibits lipoprotein lipase and hepatic lipase and decreases the chylomicrons in hepatic cells. ${ }^{30,31}$ AR $\beta 3$ protein, expressed mainly in visceral adipose tissue, ${ }^{32,33}$ contributes to both lipolysis and the delivery of free fatty acids. Fas is the main gene that controls cell death by inducing apoptosis. A previous study indicated that Fas and Fas ligand influenced the immune reconstitution induced by ART. ${ }^{34}$

In Thailand, the National Access to Antiretroviral Care program started in 2002 using standard regimens with GPOVIR (a combination of $\mathrm{d} 4 \mathrm{~T}, 3 \mathrm{TC}$, and nevirapine) as the first line of ART. The present study was performed to determine whether these genetic polymorphisms found in the Italian cohort also mediate the emergence of LA or LD in HIVinfected patients starting ART in Thailand in consideration of the relevance of these side effects in the currently used regi- mens and of the differences in ethnicity, alimentation, and way of life of the Thai population.

\section{Materials and Methods}

\section{Study design}

HIV-1-infected individuals receiving ART at Bamrasnaradura Infectious Diseases Institute, Nonthaburi, Thailand were enrolled in this study. LA was defined as the presence of fat loss at any site of the body (face, arms, legs, or buttocks). LD was defined as LA combined with fat accumulation diagnosed at the same time. Fat accumulation was defined as the presence of at least one alteration, such as buffalo hump, or fat accumulation in the breast, abdomen, neck, or lipomas. To qualify, the alteration had to be recognized by both the patient and the physician. ${ }^{35}$ Most patients who developed LA or LD changed regimen for those without d4T. A $200 \mu \mathrm{l}$ sample of whole blood was collected from each patient and stored at $-20^{\circ} \mathrm{C}$ until DNA extraction. The genotypes of ApoC3 -455, AR $\beta 3$ cod64, and Fas - 670 were compared between patients who developed LA or LD and those who did not. Patients' age, gender, transmission route, CD4 counts at pre-ART and at 1 year post-ART (cells $/ \mu \mathrm{l}$ ), drug regimens, and duration of therapy were obtained from their medical records. Lipid profile data were obtained from patients' records of serum biochemical tests. Blood for this test was collected when patients were in the fasting state; however, not all patients had serum biochemical test data as the test incurs extra costs for patients. All participants signed an informed consent form. The study was approved by the institutional ethical committees at the Bamrasnaradura Infectious Diseases Institute and Department of Disease Control, Ministry of Public Health, Thailand.

\section{DNA extraction}

Genomic DNA was extracted from $200 \mu$ l of each whole blood sample using a QIAamp DNA Blood Mini Kit (QIAGEN, Hilden, Germany) according to the manufacturer's instructions. $^{36}$

\section{Genotyping}

Genotyping of Fas gene promoter polymorphism, A-670G (rs1800682). Polymerase chain reaction (PCR) and restriction fragment length polymorphism analysis for Fas A-670G, modified from a previously published technique, ${ }^{37}$ was conducted with the primers 5'-CTACCTAAGAGCTATCTA CCGTTC-3' and 5'-GGCTGTCCATGTTGTGGCTGC-3'. The PCR product was digested with the restriction enzyme MvaI (Roche Biochemicals, Mannheim, Germany) at $37^{\circ} \mathrm{C}$ overnight. Two polymorphic alleles could be distinguished on the basis of restriction length polymorphisms (188 bp for $\mathrm{G}$ and $232 \mathrm{bp}$ for A).

Genotyping of ApoC3 gene promoter polymorphism, T455C (rs2854116). TaqMan SNP assay was performed using the StepOne real-time PCR system (Applied Biosystems, Foster City, CA) with primers (5'-GAGCTCAGCCCCTG TAACCAG-3' and 5'-ACACAGCCTGGAGTAGAGGG-3') and TaqMan MGB probes (5'-VIC-CTCCAAACACCCCMGB-3' for the $\mathrm{C}$ allele and 5'-FAM-TTTACTCCAAA CATCC-MGB-3' for the T allele). 
Genotyping of $A R \beta 3$ gene coding polymorphism, Tcod64C (rs4994). TaqMan SNP assay was performed with a TaqMan SNP assay kit (C__2215549_20; Applied Biosystems).

\section{Statistical analysis}

Person-year analysis was conducted to investigate a single endpoint: the incidence of LA or LD. If the patient was diagnosed as both LA and LD, the earlier date of the first diagnosis was used as the endpoint. We focused on the time to the occurrence of the first event. Person-years at risk were calculated from the start date of ART until the last available followup or development of the event, whichever occurred first. The Poisson regression univariate model was used to determine whether the genetic polymorphisms as well as patients' age, gender, transmission route, CD4 counts at pre-ART and at 1 year post-ART, and starting drug regimes were predictors of LA or LD. Associations were expressed as incidence rate ratio (IRR) and corresponding 95\% confidence interval (CI). Factors showing significant association with LA or LD were then included as covariates in the Poisson regression multivariate model to adjust for their possible confounding effects. Starting drug regimens were grouped into either $\mathrm{d} 4 \mathrm{~T}$-containing regimens or other backbone regimens. Continuous variables were compared using the Wilcoxon signed rank test for paired samples and Kruskal-Wallis test for unpaired samples. A variable was considered significant at $p<0.05$.

\section{Results}

Incidences of $L A$ and/or LD in HIV-1-infected Thai patients undergoing $A R T$

A total of $829 \mathrm{HIV}-1$-infected individuals who had started ART were enrolled in this study at the Bamrasnaradura Infectious Diseases Institute, Nonthaburi, Thailand, from April 2008 to August 2009. Patient demographic data are shown in Table 1 . The study population consisted of 478 males $(57.7 \%)$ and 351 females (42.3\%). Most of the patients contracted infection through sexual contact. Almost half of the patients started ART immediately after being diagnosed with HIV infection. Median CD4 count per microliter pre-ART was 45

Table 1. Demographic Data of All the Patients

\begin{tabular}{lc}
\hline Demographic data & $\mathrm{n}=829$ \\
\hline Mean age (SD) years & $41.12(7.77)$ \\
Male (\%) & $478(57.66)$ \\
Transmission & $806(97.23)$ \\
$\quad$ Sexual (\%) & $8(0.97)$ \\
$\quad$ Intravenous drug user (\%) & $15(1.81)$ \\
$\quad$ Unknown (\%) & $45(15,127.5)$ \\
Median baseline CD4 (cells/ $\mu \mathrm{l})(\mathrm{IQR})$ & $210.5(142,305)$ \\
Median CD4 (cells/ $\mu \mathrm{l})$ after treatment & \\
$\quad$ IQR) & $2.63(1.67,4.00)$ \\
Median duration of therapy before & \\
$\quad$ onset of lipoatrophy or & \\
lipodystrophy (years, IQR) $(n=270)$ & $5.53(4.10,7.18)$ \\
Median duration of therapy of & \\
$\quad$ nonlipoatrophy or nonlipodystrophy & \\
$\quad$ (years, IQR) $(n=559)$ & \\
\hline
\end{tabular}

$\mathrm{SD}$, standard deviation; IQR, interquartile range. and that post-ART (after 1 year) was 210.5. The mean followup period was 4.85 years $(\mathrm{SD}=2.42)$.

We first combined patients with LA and those with LD for analysis, as fat loss was commonly observed in both LA and LD cases. Among the 829 patients, 270 (32.6\%) were diagnosed with LA or LD within the observation period. We kept on monitoring the other $559(67.4 \%)$ until the end of the observation period and found that they developed neither LA nor LD (non-LA/LD cases). The median duration of therapy until diagnosis was 2.63 years for the LA or LD cases and 5.53 years for the non-LA/LD cases. In a follow-up of 4019.8 person-years, the incidence rate of LA or LD was 6.70 per 100 person-years. LA or LD cases were found more frequently in females $(40.7 \%)$ than in males $(26.6 \%)$, and the incidence rate per 100 person-years for females (9.11) was significantly higher than that for males (5.18) $(\mathrm{IRR}=1.76,95 \% \mathrm{CI}=1.37-$ 2.25, $p<0.001$ ) (Table 2). Patients using d4T/3TC backbone regimens as starting drugs showed a significantly higher incidence rate per 100 person-years (7.71) than those with other non-d4T-containing (mostly AZT/3TC) regimens (3.49) $(\mathrm{IRR}=2.21,95 \% \mathrm{CI}=1.53-3.28, p<0.001)$ (Table 2). These findings were consistent with those of previous studies in other ethnic groups. ${ }^{9,20,29,38,39}$ In contrast, age, transmission route, and CD4 counts pre-ART and at 1 year post-ART did not significantly affect the incidence of LA or LD (Table 2).

\section{Fas $-670 A A$, but not ApoC3 - 455 or $A R \beta 3$ cod64 genotype, affects incidence of $L A$ or $L D$ in HIV-1-infected Thai patients}

To elucidate the possible effects of genetic polymorphisms on the development of LA or LD, we determined the genotypes of Fas -670, ApoC3 - 455, and ARß3 cod64 of 829 HIV-1-infected Thai patients. LA or LD cases were found significantly more frequently among patients with the Fas -670AA genotype than in those with other Fas -670 genotypes $(\mathrm{IRR}=1.41,95 \% \mathrm{CI}=1.06-1.86, p=0.015$, Table 2$)$. The Fas -670AA genotype was found in $25.9 \%$ of the LA or LD cases and in $20.2 \%$ of the non-LA/LD cases during the observation period. Increased frequency of the Fas -670AA genotype in LA or LD cases was observed in both males and females (data not shown). In cases of $A p o C 3-455$ and $A R \beta 3$ cod64 genotypes, however, there were no statistically significant differences in the frequency of LA or LD between groups (Table 2). Adjustment for gender and starting drug regimens in multivariate Poisson regression analysis resulted in a slightly higher IRR for Fas -670AA $(1.47,95 \%$ CI=1.12-194, $p=0.005$, Table 2 ). This difference was statistically significant after correction for multiple testing of three SNPs $(p=0.015)$.

\section{Fas-670AA genotype affects incidence of $L A$ but not that of $L D$ in HIV-1-infected Thai patients}

Among 270 LA and/or LD cases, 148 were diagnosed as LA singly and 105 were diagnosed as LD singly. There were 17 cases diagnosed as LA first who then subsequently developed fat accumulation. These 17 cases were grouped as LD cases. The median durations of therapy until diagnosis were 2.58 years for LA and 2.83 years for LD cases. When we analyzed LA and LD separately, females showed a higher IRR in both LA $(1.60,95 \% \mathrm{CI}=1.14-2.24, p=0.005)$ and $\operatorname{LD}(2.31,95 \%$ $\mathrm{CI}=1.59-3.38, p<0.001$ ) (Tables 3 and 4)., Similarly, d4Tcontaining regimens showed significantly higher IRR in both 
Table 2. Univariate and Multivariate Analysis of All Patients $(N=829)$

\begin{tabular}{|c|c|c|c|c|c|c|c|}
\hline \multirow[b]{2}{*}{ Factors } & \multirow[b]{2}{*}{ Events $^{1}$} & \multirow[b]{2}{*}{ Person-years } & \multirow{2}{*}{$\begin{array}{c}\text { Events/100 } \\
\text { person-years }\end{array}$} & \multicolumn{2}{|l|}{ Crude } & \multicolumn{2}{|c|}{ Adjusted $^{2}(\mathrm{n}=829)$} \\
\hline & & & & $\operatorname{IRR}(95 \% \mathrm{CI})$ & p-value & $\operatorname{IRR}(95 \% \mathrm{CI})$ & $\mathrm{p}$-value \\
\hline \multicolumn{8}{|l|}{ Gender } \\
\hline Male & 127 & 2449.9 & 5.18 & 1 & & & \\
\hline Female & 143 & 1569.9 & 9.11 & $1.76(1.37-2.25)$ & $<0.001$ & $1.70(1.33-2.16)$ & $<0.001$ \\
\hline \multicolumn{8}{|l|}{ Transmission } \\
\hline Unknown ${ }^{3}$ & 7 & 95.9 & 7.3 & 1 & & & \\
\hline Sexual & 263 & 3924.0 & 6.7 & $0.92(0.44-2.31)$ & 0.782 & & \\
\hline \multicolumn{8}{|l|}{ NRTIs } \\
\hline No-d4T & $33^{4}$ & 945.8 & 3.49 & 1 & & & \\
\hline $\mathrm{d} 4 \mathrm{~T}$ & $237^{5}$ & 3074.0 & 7.71 & $2.21(1.53-3.28)$ & $<0.001$ & $2.05(1.42-2.96)$ & $<0.001$ \\
\hline Age ×10 (years) & & & & $0.87(0.74-1.02)$ & 0.090 & & \\
\hline CD4 at baseline ${ }^{5}$ & & & & $0.9988(0.9973-1.0003)$ & 0.107 & & \\
\hline CD4 after therapy & & & & $0.9497(0.9987-1.0005)$ & 0.458 & & \\
\hline \multicolumn{8}{|l|}{ Fas -670} \\
\hline $\mathrm{AG} / \mathrm{GG}$ & 200 & 3221.6 & 6.21 & 1 & & & \\
\hline AA & 70 & 798.2 & 8.77 & $1.41(1.06-1.86)$ & 0.015 & 1.47 (1.12-1.94) & 0.005 \\
\hline \multicolumn{8}{|l|}{ АроС $3-455$} \\
\hline $\mathrm{CT} / \mathrm{TT}$ & 206 & 3139.0 & 6.56 & 1 & & & \\
\hline $\mathrm{CC}$ & 64 & 880.9 & 7.27 & $1.11(0.82-1.47)$ & 0.474 & & \\
\hline \multicolumn{8}{|l|}{$A R \beta 3 \operatorname{cod} 64$} \\
\hline $\mathrm{CC} / \mathrm{CT}$ & 58 & 815.8 & 7.11 & 1 & & & \\
\hline $\mathrm{TT}$ & 212 & 3204.0 & 6.62 & $0.93(0.69-1.27)$ & 0.621 & & \\
\hline
\end{tabular}

${ }^{1}$ Diagnosis of lipoatrophy or lipodystrophy.

${ }^{2}$ Gender, NRTIs, and Fas -670 were included as covariates.

${ }^{3}$ Including eight intravenous drug users.

${ }^{4}$ No-d4T group mainly used AZT. One case had received ddI instead of AZT as an initial regimen.

${ }^{5} \mathrm{CD} 4$ cells $/ \mu \mathrm{l}$.

IRR, incidence rate ratios; NRTIs, nucleoside reverse transcriptase inhibitors; d4T, stavudine.

LA (2.46, 95\% CI $=1.48-4.36, p<0.001)$ and $\operatorname{LD}(2.10$, $95 \% \mathrm{CI}=1.23-3.80, p=0.003$ ) (Tables 3 and 4 ). In the case of the Fas -670AA genotype, however, significantly higher IRR was observed only in LA $(1.68,95 \% \mathrm{CI}=1.15-2.41$, $p=0.006)$ but not in LD $(1.19,95 \% \mathrm{CI}=0.74-1.83, p=0.433)$ (Tables 3 and 4). The statistical significance of higher IRR of LA for Fas -670AA did not change after adjustment for gender and starting drug regimens in multivariate Poisson regression analysis $(1.72,95 \% \mathrm{CI}=1.20-2.45, p=0.003$, Table $3)$. The difference was statistically significant even after correction for multiple testing of three SNPs in two groups (LA or LD) $(p=0.018)$. These results suggested that the Fas -670 genotype affects LA without fat accumulation.

\section{Lipid profiles of HIV-1-infected Thai patients}

We analyzed the serum lipid profiles of the patients. From the records of 829 patients, serum cholesterol levels were obtained in 610 and 628 cases at the first and last measurement of the observation period, respectively. Serum triglyceride (TG) levels were obtained in 646 and 716 cases at the first and last measurement, respectively. Serum HDL levels were obtained in 393 and 367 cases at the first and last measurement, respectively. Serum low-density lipoprotein (LDL) levels were obtained in 382 and 438 cases at the first and last measurement, respectively. Serum cholesterol levels showed a normal distribution, while serum TG, HDL, and LDL levels did not. Therefore, we used a nonparametric method to evaluate the statistical significance of differences in patient lipid profiles. Slight increases in serum cholesterol levels were observed in the LA (from median 194.5 to $206 \mathrm{mg} / \mathrm{dl}$, $p=0.016$ ), LD (from median 194 to $205 \mathrm{mg} / \mathrm{dl}, p=0.001$ ), and non-LA/LD cases (from median 195 to $200 \mathrm{mg} / \mathrm{dl}, p=0.033$ ) during ART (Table 5). Similarly, significant increases in TG were observed in the LA (from median 130 to $183.5 \mathrm{mg} / \mathrm{dl}$, $p=0.019$ ) and LD (from median 122 to $165.5 \mathrm{mg} / \mathrm{dl}, p<0.001$ ), but not in non-LA/LD cases (from median 138 to $148.5 \mathrm{mg}$ / dl, $p=0.359$; Table 5). Accordingly, the LA and LD cases showed significantly higher TG levels than the non-LA/LD cases at the last measurement ( $p=0.007$; Table 5). These results indicated that lipid metabolism in LA and LD cases was more severely damaged by ART than that in non-LA/LD cases. It should also be noted here that the LA and LD cases showed weak but clear trends toward lower TG levels than non-LA/LD cases at the first measurement ( $p=0.091$; Table 5). In fact, when combined, the LA and LD cases showed significantly lower TG levels (median $122 \mathrm{mg} / \mathrm{dl}$ ) than the non-LA/LD cases (median $138 \mathrm{mg} / \mathrm{dl}$ ) at the first measurement $(p=0.049)$. On the other hand, HDL and LDL levels remained almost unchanged during the treatment period in the LA and LD, but non-LA/LD cases showed a slight decrease in LDL (from median 137 to $132.5 \mathrm{mg} / \mathrm{dl}, p=0.026$; Table 5).

As the LA and LD cases showed similar lipid profiles, we combined the LA and LD cases again and analyzed the effects of patients' genotypes on the lipid profile together. The results indicated that the ApoC3 -455CC genotype was associated with decreased serum cholesterol levels in non-LA/LD cases at the last measurement ( $p=0.035$; Table 6). However, this association was not observed in LA and LD cases $(p=0.393$; 
Table 3. Lipoatrophy: Rate of Incidence and Multivariate Analysis $(N=707)$

\begin{tabular}{|c|c|c|c|c|c|c|c|}
\hline \multirow[b]{2}{*}{ Factors } & \multirow[b]{2}{*}{ Events $^{1}$} & \multirow[b]{2}{*}{ Person-years } & \multirow{2}{*}{$\begin{array}{c}\text { Events/100 } \\
\text { person-years }\end{array}$} & \multicolumn{2}{|l|}{ Crude } & \multicolumn{2}{|c|}{ Adjusted $^{2}(\mathrm{n}=707)$} \\
\hline & & & & $\operatorname{IRR}(95 \% C I)$ & $\mathrm{p}$-value & $\operatorname{IRR}(95 \% \mathrm{CI})$ & p-value \\
\hline \multicolumn{8}{|l|}{ Gender } \\
\hline Male & 76 & 2282.1 & 3.33 & 1 & & & \\
\hline Female & 72 & 1350.9 & 5.33 & $1.60(1.14-2.24)$ & 0.005 & $1.56(1.13-2.16)$ & 0.007 \\
\hline \multicolumn{8}{|l|}{ Transmission } \\
\hline Unknown & 3 & 85.2 & 3.52 & 1 & & & \\
\hline Sexual & 145 & 3547.8 & 4.09 & $1.16(0.39-5.69)$ & 0.865 & & \\
\hline \multicolumn{8}{|l|}{ NRTIs } \\
\hline No-d4T & 17 & 880.5 & 1.93 & 1 & & & \\
\hline $\mathrm{d} 4 \mathrm{~T}$ & 131 & 2752.5 & 4.76 & $2.46(1.48-4.36)$ & $<0.001$ & $2.32(1.40-3.85)$ & 0.001 \\
\hline Age×10 (years) & & & & $0.88(0.71-1.08)$ & 0.228 & & \\
\hline CD4 at baseline ${ }^{3}$ & & & & $0.9985(0.9964-1.0006)$ & 0.151 & & \\
\hline CD4 after therapy ${ }^{3}$ & & & & 0.9991 (0.9979-1.0003) & 0.151 & & \\
\hline \multicolumn{8}{|l|}{ Fas -670} \\
\hline $\mathrm{AG} / \mathrm{GG}$ & 105 & 2920.4 & 3.59 & 1 & & & \\
\hline AA & 43 & 712.6 & 6.03 & $1.68(1.15-2.41)$ & 0.006 & $1.72(1.20-2.45)$ & 0.003 \\
\hline \multicolumn{8}{|l|}{ АроС $3-455$} \\
\hline $\mathrm{CT} / \mathrm{TT}$ & 118 & 2866.1 & 4.12 & 1 & & & \\
\hline $\mathrm{CC}$ & 30 & 766.9 & 3.91 & $0.95(0.61-1.43)$ & 0.818 & & \\
\hline \multicolumn{8}{|l|}{$A R \beta 3 \operatorname{cod} 64$} \\
\hline $\mathrm{CC} / \mathrm{CT}$ & 38 & 748.0 & 5.08 & 1 & & & \\
\hline $\mathrm{TT}$ & 110 & 2885.0 & 3.81 & $0.75(0.51-1.12)$ & 0.134 & & \\
\hline
\end{tabular}

${ }^{1}$ Diagnosis of lipoatrophy.

${ }^{2}$ Gender, NRTIs, and Fas -670 were included as covariates.

${ }^{3} \mathrm{CD} 4$ cells $/ \mu \mathrm{l}$.

IRR, incidence rate ratios; NRTIs, nucleoside reverse transcriptase inhibitors; $d 4 T$, stavudine.

Table 4. Lipodystrophy: Rate of Incidence and Multivariate Analysis $(N=681)$

\begin{tabular}{|c|c|c|c|c|c|c|c|}
\hline \multirow[b]{2}{*}{ Factors } & \multirow[b]{2}{*}{ Events $^{1}$} & \multirow[b]{2}{*}{ Person-years } & \multirow{2}{*}{$\begin{array}{l}\text { Events/100 } \\
\text { person-years }\end{array}$} & \multicolumn{2}{|l|}{ Crude } & \multicolumn{2}{|c|}{ Adjusted $^{2}(\mathrm{n}=681)$} \\
\hline & & & & $\operatorname{IRR}(95 \% \mathrm{CI})$ & p-value & $\operatorname{IRR}(95 \% \mathrm{CI})$ & p-value \\
\hline \multicolumn{8}{|l|}{ Gender } \\
\hline Male & 51 & 2234.3 & 2.28 & 1 & & & \\
\hline Female & 71 & 1346.3 & 5.27 & $2.31(1.59-3.38)$ & $<0.001$ & $2.19(1.53-3.15)$ & $<0.001$ \\
\hline \multicolumn{8}{|l|}{ Transmission } \\
\hline Unknown & 4 & 86.0 & 4.65 & 1 & & & \\
\hline Sexual & 118 & 3494.5 & 3.38 & $0.73(0.28-2.71)$ & 0.508 & & \\
\hline \multicolumn{8}{|l|}{ NRTIs } \\
\hline No-d4T & 16 & 860.3 & 1.86 & 1 & & & \\
\hline $\mathrm{d} 4 \mathrm{~T}$ & 106 & 2720.2 & 3.90 & $2.10(1.23-3.80)$ & 0.003 & $1.82(1.07-3.09)$ & 0.027 \\
\hline Age×10 (years) & & & & $0.85(0.67-1.07)$ & 0.171 & & \\
\hline CD4 at baseline ${ }^{3}$ & & & & $0.9988(0.9966-1.0010)$ & 0.278 & & \\
\hline CD4 after therapy ${ }^{3}$ & & & & $1.0000(0.9990-1.0014)$ & 0.696 & & \\
\hline \multicolumn{8}{|l|}{ Fas -670} \\
\hline AG/GG & 95 & 2888.0 & 3.29 & 1 & & & \\
\hline $\mathrm{AA}$ & 27 & 692.6 & 3.90 & 1.19 (0.74-1.83) & 0.433 & 1.27 (0.83-1.95) & 0.278 \\
\hline \multicolumn{8}{|l|}{ ApoС $3-455$} \\
\hline $\mathrm{CT} / \mathrm{TT}$ & 88 & 2781.9 & 3.16 & 1 & & & \\
\hline CC & 34 & 798.7 & 4.26 & $1.34(0.88-2.02)$ & 0.148 & & \\
\hline \multicolumn{8}{|l|}{$A R \beta 3 \operatorname{cod} 64$} \\
\hline $\mathrm{CC} / \mathrm{CT}$ & 20 & 714.5 & 2.80 & 1 & & & \\
\hline $\mathrm{TT}$ & 102 & 2866.1 & 3.56 & $1.27(0.78-2.17)$ & 0.328 & & \\
\hline
\end{tabular}

${ }^{1}$ Diagnosis of lipoatrophy.

${ }^{2}$ Gender, NRTIs, and Fas -670 were included as covariates.

${ }^{3} \mathrm{CD} 4$ cells $/ \mu \mathrm{l}$.

Lipodystrophy cases included 17 cases diagnosed with both lipoatrophy and lipodystrophy.

IRR, incidence rate ratios; NRTIs, nucleoside reverse transcriptase inhibitors; d4T, stavudine. 
Table 5. Lipid Profile of Patients

\begin{tabular}{|c|c|c|c|c|c|c|c|c|c|c|}
\hline \multirow[b]{2}{*}{ Lipid profile } & \multicolumn{3}{|c|}{$L A$ cases $^{1}$} & \multicolumn{3}{|c|}{$L D$ cases $^{2}$} & \multicolumn{3}{|c|}{ Non-LA/LD cases $^{3}$} & \multirow[b]{2}{*}{$\mathrm{p}$-value } \\
\hline & $\mathrm{n}$ & Median & $I Q R$ & $\mathrm{n}$ & Median & $I Q R$ & $\mathrm{n}$ & Median & $I Q R$ & \\
\hline \multicolumn{11}{|c|}{ Cholesterol (mg/dl) } \\
\hline First test ${ }^{5}$ & 96 & 194.5 & $165.25-231.25$ & 77 & 194 & $159.00-216.50$ & 437 & 195 & $160.00-224.00$ & 0.507 \\
\hline $\begin{array}{l}\text { Last test }^{6} \\
p \text {-value }\end{array}$ & 121 & $\begin{array}{l}206 \\
0.016\end{array}$ & $177.50-236.00$ & 95 & $\begin{array}{l}205 \\
0.001\end{array}$ & $180.00-239.00$ & 412 & $\begin{array}{l}200 \\
0.033\end{array}$ & $176.500-227.75$ & 0.106 \\
\hline \multicolumn{11}{|l|}{ TG (mg/dl) } \\
\hline First test ${ }^{5}$ & 98 & 130 & $92.25-190.25$ & 89 & 122 & $88.00-164.50$ & 459 & 138.0 & $95.00-201.00$ & 0.091 \\
\hline $\begin{array}{l}\text { Last test }^{6} \\
\text { p-value }\end{array}$ & 140 & $\begin{array}{l}183.5 \\
0.019\end{array}$ & $109.50-285.00$ & 116 & $\begin{array}{c}165.5 \\
<0.001\end{array}$ & $103.75-256.25$ & 460 & $\begin{array}{l}148.5 \\
0.359\end{array}$ & $97.00-224.75$ & 0.007 \\
\hline \multicolumn{11}{|c|}{ HDL (mg/dl) } \\
\hline First test ${ }^{5}$ & 43 & 50 & $40.00-67.00$ & 45 & 51 & $44.00-70.00$ & 305 & 50 & $40.00-62.00$ & 0.648 \\
\hline $\begin{array}{l}\text { Last test }^{6} \\
p \text {-value }\end{array}$ & 63 & $\begin{array}{c}52 \\
0.933\end{array}$ & $42.00-66.00$ & 51 & $\begin{array}{c}52 \\
0.885\end{array}$ & $42.00-63.00$ & 253 & $\begin{array}{c}50 \\
0.392\end{array}$ & $40.00-62.00$ & 0.419 \\
\hline \multicolumn{11}{|l|}{ LDL (mg/dl) } \\
\hline First test ${ }^{5}$ & 41 & 136 & $117.00-174.00$ & 51 & 133 & $116.00-168.00$ & 290 & 137 & $108.00-167.00$ & 0.731 \\
\hline $\begin{array}{l}\text { Last test }^{6} \\
p \text {-value }\end{array}$ & 70 & $\begin{array}{l}135.5 \\
0.777\end{array}$ & $107.75-166.25$ & 88 & $\begin{array}{l}136.5 \\
0.735\end{array}$ & $114.25-165.75$ & 280 & $\begin{array}{l}132.5 \\
0.026\end{array}$ & $111.00-157.00$ & 0.295 \\
\hline
\end{tabular}

${ }^{1}$ Lipoatrophy cases.

${ }^{2}$ Lipodystrophy cases.

${ }^{3}$ Patients without lipoatrophy or lipodystrophy.

${ }^{4}$ Kruskal-Wallis test.

${ }^{5}$ The first measurement after patients started antiretroviral therapy.

${ }^{6}$ The last measurement of the observation period. For LA and LD cases, this corresponded to the diagnosis of LA and LD, respectively.

${ }^{7}$ Wilcoxon signed rank test.

LA, lipoatrophy; LD, lipodystrophy; IQR, interquartile range; TG, triglyceride; HDL, high-density lipoprotein; LDL, low-density lipoprotein.

Table 6) or at the first measurement in both LA and LD cases and non-LA/LD cases ( $p=0.254$ and $p=0.583$, respectively). The ApoC3 - 455CC genotype was also found to be associated with elevated serum TG levels in the LA and LD cases at the time of LA or LD diagnosis ( $p=0.021$; Table 6$)$. In the nonLA/LD cases, the ApoC3 - 455CC genotype had virtually no effect on serum TG levels. These results suggested that the ApoC3 -455CC genotype promotes dysregulation of lipid metabolism in LA or LD cases, even though this allele had no deleterious effect on the onset of LA or LD (Table 2). On the other hand, the ApoC3 -455CC genotype affected neither HDL nor LDL serum levels (data not shown). The $A R \beta 3$ cod64 genotype had no effect on the serum lipid data of any patient group (Table 6). Similarly, Fas -670AA, which was found to be significantly associated with LA, did not show any effects on serum lipid levels (Table 6).

\section{Discussion}

In the present study, we evaluated the influence of SNPs involved in apoptosis and lipid metabolism on developing LA or LD in Thai HIV-1 patients. Specifically, we analyzed the SNPs of the Fas A-670G, ApoC3 T-455C, and AR $\beta 3$ Tcod64C in patients undergoing ART.

Of the SNPs investigated, our findings indicated that the AA genotype of Fas - 670 was significantly associated with the risk of LA but not that of LD. This result is consistent with that of a previous study in Italian HIV patients by Zanone Poma et al. ${ }^{29} \mathrm{It}$ was suggested that adipocyte apoptosis induced by mitochondrial toxicity of NRTIs was the primary mechanism involved in LA. ${ }^{15}$ Consistent with this suggestion, increased Fas gene expression levels were observed in adipose tissue of HIV-1 patients with NRTI-associated LA. ${ }^{40}$ The Fas A-670G polymorphism is located in the $\gamma$-interferon activation site, to which transcription factors such as signal transducer and activator of transcription (STAT) bind. ${ }^{41}$ Therefore, this SNP may affect the level of Fas gene transcription and may induce apoptosis, consequently increasing the risk of LA. The Fas A-670G polymorphism has been reported to be associated with several autoimmune diseases and inflammatory disorders, ${ }^{41-43}$ which may involve a mechanism similar to LA. The frequency of the AA genotype of Fas -670 in 829 HIV-1-infected Thais was $22.1 \%$, which is similar to the percentages in Europeans and Japanese but is markedly higher than that in Africans. As Fas - 670AA caused a 70\% increase in risk of LA, this genotype is a candidate for future pretherapy genetic screening, although it is still necessary to find other SNPs that increase the risk of LA for accurate screening. It is also necessary to confirm our findings on Fas -670AA in a larger patient cohort.

On the other hand, the frequency distribution of the $A R \beta 3$ cod64 and ApoC3 - 455 genotypes was not significantly different between LA or LD cases and non-LA/LD cases. The $A R \beta 3$ Tcod64C polymorphism failed to show any effect on lipid metabolism among Thai patients in this study. The results for $A R \beta 3$ cod64 were consistent with a previous report that showed no association of this polymorphism with lipid metabolism during weight loss in obese subjects. ${ }^{44}$ However, in the Italian cohort, this genotype was associated with the risk of developing LA. ${ }^{29}$ Several studies have reported that people with this SNP showed an increased risk of developing obesity and glucose intolerance, ${ }^{32,33}$ whereas other studies failed to find any correlation between this mutation and body mass index. ${ }^{45,46}$

The results for ApoC3 - 455 were also not consistent with those of the Italian cohort, which showed an association of the 


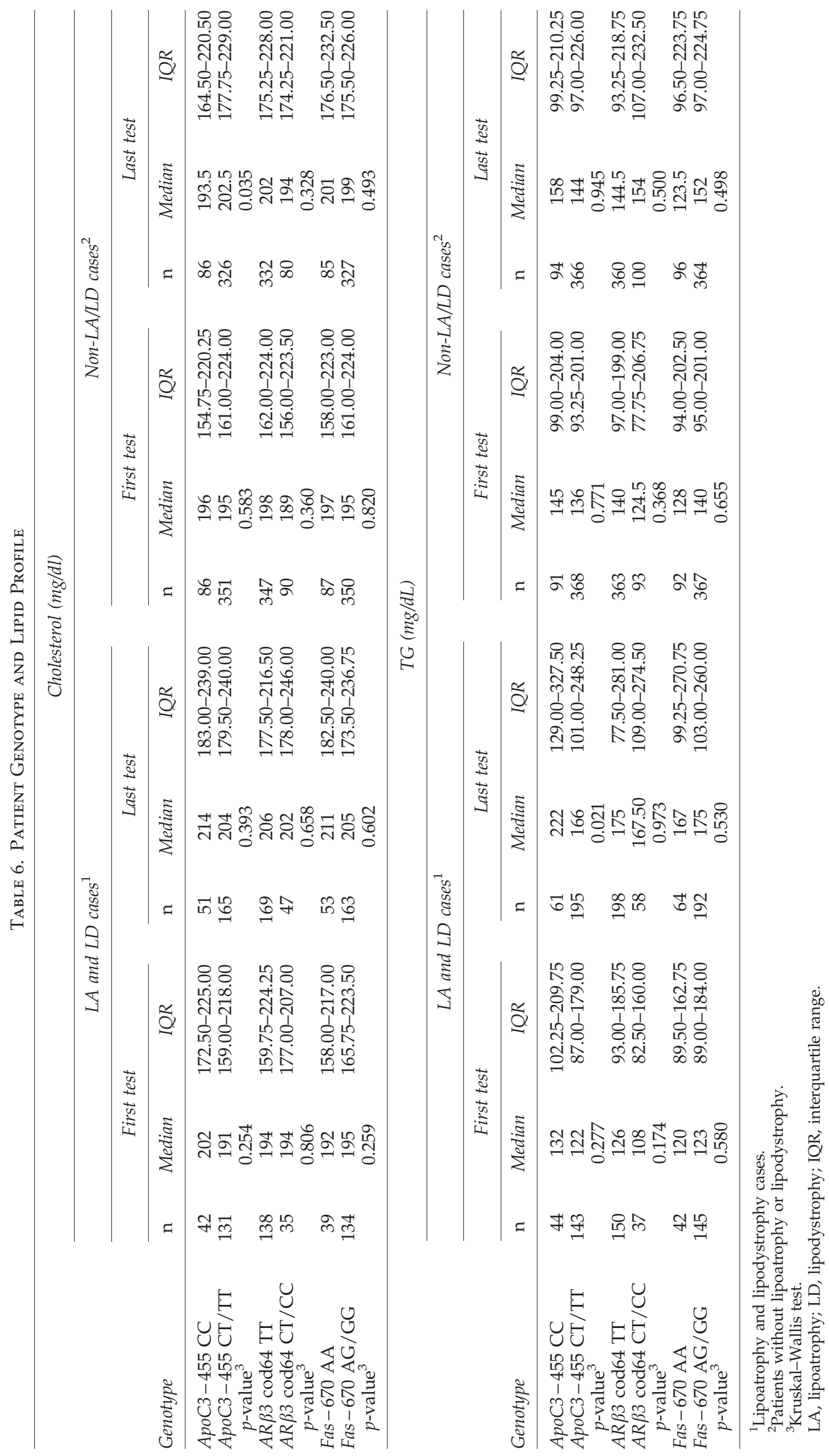


ApoC3 -455T allele with LA. However, it was also reported that the ApoC3 $-455 \mathrm{C}$ but not the ApoC3 -455T allele was associated with metabolic syndrome. ${ }^{47}$ In fact, a recent study in French HIV patients showed that the ApoC3 -455C but not the ApoC3 - 455T allele is associated with the severity of ARTinduced dyslipidemia and occurrence of LD. ${ }^{48,49}$ Therefore, the precise role of the ApoC3 T-455C polymorphism in LA or LD during ART should be carefully reevaluated in a larger cohort of HIV patients.

Nevertheless, our study also showed that the ApoC3 -455CC genotype was associated with elevated serum levels of TG, which was consistent with the findings of a previous report showing that the ApoC3 $-455 \mathrm{C}$ allele was associated with metabolic syndrome. ${ }^{47}$ These data suggest that the mechanism underlying the promotion of LA and LD in HIV-infected individuals receiving ART may be different from that promoting metabolic syndrome. However, the differences in results may be due to ethnic differences in the cohorts. It was reported that genetic polymorphisms in hepatic lipase showed different effects on plasma lipid levels in different ethnic groups. ${ }^{50}$ Foulkes et al. found race- and ethnic-specific differences in plasma lipid levels under ART, as well as differences in the influence of ApoC3 T-455C and the other SNP in ApoC3 gene on the development of protease inhibitor-related hypertriglyceridemia. ${ }^{51}$ Further studies including reevaluation of these SNPs in larger patient cohorts are therefore necessary to elucidate the precise mechanisms underlying LA and LD in HIV-infected individuals receiving ART.

In conclusion, the Fas -670AA genotype, but not the ApoC3 -455 or $A R \beta 3$ cod64 genotypes, affected the incidence of LA in HIV-1-infected Thai patients. None of these alleles affected the incidence of LD. On the other hand, the ApoC3 $-455 C C$, but not the $A R \beta 3$ cod64 genotype, affected the serum levels of TG.

\section{Acknowledgments}

We thank Ms. Taksin Pimpak for her help in statistical analysis, Professor Massimo Galli at the University of Milan for his support, and all the participants in this study. This work was supported by grants from the Health Science Foundation, the Ministry of Education, Culture, Sports, Science, and Technology, and the Ministry of Health, Labour, and Welfare, Japan.

\section{Author Disclosure Statement}

No competing financial interests exist.

\section{References}

1. Behrens G, Dejam A, Schmidt $H$, et al.: Impaired glucose tolerance, beta cell function and lipid metabolism in HIV patients under treatment with protease inhibitors. AIDS 1999;13:F63-70.

2. Tsiodras S, Mantzoros C, Hammer S, and Samore M: Effects of protease inhibitors on hyperglycemia, hyperlipidemia, and lipodystrophy: A 5-year cohort study. Arch Intern Med 2000;160:2050-2056.

3. Vigouroux C, Gharakhanian S, Salhi Y, et al.: Diabetes, insulin resistance and dyslipidaemia in lipodystrophic HIVinfected patients on highly active antiretroviral therapy (HAART). Diabetes Metab 1999;25:225-232.
4. Carr A: HIV lipodystrophy: Risk factors, pathogenesis, diagnosis and management. AIDS 2003;17(Suppl 1):S141-148.

5. Birkus G, Hitchcock MJ, and Cihlar T: Assessment of mitochondrial toxicity in human cells treated with tenofovir: Comparison with other nucleoside reverse transcriptase inhibitors. Antimicrob Agents Chemother 2002;46:716-723.

6. Maggiolo F, Roat E, Pinti M, et al.: Mitochondrial changes during D-drug-containing once-daily therapy in HIV-positive treatment-naive patients. Antivir Ther 2010;15:51-59.

7. Giralt M, Domingo P, Guallar JP, et al.: HIV-1 infection alters gene expression in adipose tissue, which contributes to HIV1/HAART-associated lipodystrophy. Antivir Ther 2006;11: 729-740.

8. Collins ML, Sondel N, Cesar D, and Hellerstein MK: Effect of nucleoside reverse transcriptase inhibitors on mitochondrial DNA synthesis in rats and humans. J Acquir Immune Defic Syndr 2004;37:1132-1139.

9. Mallal SA, John M, Moore CB, James IR, and McKinnon EJ: Contribution of nucleoside analogue reverse transcriptase inhibitors to subcutaneous fat wasting in patients with HIV infection. AIDS 2000;14:1309-1316.

10. van Vonderen MG, van Agtmael MA, Hassink EA, et al.: Zidovudine/lamivudine for HIV-1 infection contributes to limb fat loss. PLoS One 2009;4:e5647.

11. Moyle G: Mechanisms of HIV and nucleoside reverse transcriptase inhibitor injury to mitochondria. Antivir Ther 2005;10(Suppl 2):M47-52.

12. Minami R, Yamamoto $M$, Takahama $S$, Ando $H$, Miyamura $\mathrm{T}$, and Suematsu E: Comparison of the influence of four classes of HIV antiretrovirals on adipogenic differentiation: The minimal effect of raltegravir and atazanavir. J Infect Chemother 2011;17:183-188.

13. Lebrecht D, Venhoff AC, Kirschner J, Wiech T, Venhoff N, and Walker UA: Mitochondrial tubulopathy in tenofovir disoproxil fumarate-treated rats. J Acquir Immune Defic Syndr 2009;51:258-263.

14. Perazella MA: Tenofovir-induced kidney disease: An acquired renal tubular mitochondriopathy. Kidney Int 2010;78:1060-1063.

15. McComsey GA, Paulsen DM, Lonergan JT, et al.: Improvements in lipoatrophy, mitochondrial DNA levels and fat apoptosis after replacing stavudine with abacavir or zidovudine. AIDS 2005;19:15-23.

16. Gallant JE, DeJesus E, Arribas JR, et al.: Tenofovir DF, emtricitabine, and efavirenz vs. zidovudine, lamivudine, and efavirenz for HIV. N Engl J Med 2006;354:251-260.

17. Benn P, Sauret-Jackson V, Cartledge J, et al.: Improvements in cheek volume in lipoatrophic individuals switching away from thymidine nucleoside reverse transcriptase inhibitors. HIV Med 2009;10:351-355.

18. Lichtenstein KA: Redefining lipodystrophy syndrome: Risks and impact on clinical decision making. J Acquir Immune Defic Syndr 2005;39:395-400.

19. Leung VL and Glesby MJ: Pathogenesis and treatment of HIV lipohypertrophy. Curr Opin Infect Dis 2011;24:43-49.

20. Galli M, Veglia F, Angarano G, et al.: Gender differences in antiretroviral drug-related adipose tissue alterations. Women are at higher risk than men and develop particular lipodystrophy patterns. J Acquir Immune Defic Syndr 2003; 34:58-61.

21. Dube MP, Komarow L, Mulligan K, et al.: Long-term body fat outcomes in antiretroviral-naive participants randomized to nelfinavir or efavirenz or both plus dual nucleosides. Dual X-ray absorptiometry results from A5005s, a substudy of 
Adult Clinical Trials Group 384. J Acquir Immune Defic Syndr 2007;45:508-514.

22. Shikuma CM, Yang Y, Glesby MJ, et al.: Metabolic effects of protease inhibitor-sparing antiretroviral regimens given as initial treatment of HIV-1 Infection (AIDS Clinical Trials Group Study A5095). J Acquir Immune Defic Syndr 2007;44:540-550.

23. Sekhar RV, Jahoor F, Pownall HJ, et al.: Severely dysregulated disposal of postprandial triacylglycerols exacerbates hypertriacylglycerolemia in HIV lipodystrophy syndrome. Am J Clin Nutr 2005;81:1405-1410.

24. Kratz M, Purnell JQ, Breen PA, et al.: Reduced adipogenic gene expression in thigh adipose tissue precedes human immunodeficiency virus-associated lipoatrophy. J Clin Endocrinol Metab 2008;93:959-966.

25. Addy CL, Gavrila A, Tsiodras S, Brodovicz K, Karchmer AW, and Mantzoros CS: Hypoadiponectinemia is associated with insulin resistance, hypertriglyceridemia, and fat redistribution in human immunodeficiency virus-infected patients treated with highly active antiretroviral therapy. J Clin Endocrinol Metab 2003;88:627-636.

26. Nagy GS, Tsiodras S, Martin LD, et al.: Human immunodeficiency virus type 1-related lipoatrophy and lipohypertrophy are associated with serum concentrations of leptin. Clin Infect Dis 2003;36:795-802.

27. Bouchard C, Tremblay A, Despres JP, et al.: The response to long-term overfeeding in identical twins. N Engl J Med 1990;322:1477-1482.

28. Fox J, Boffito M, and Winton A: The clinical implications of anti-retroviral pharmacogenomics. Pharmacogenomics 2006; 7:587-596.

29. Zanone Poma B, Riva A, Nasi M, et al.: Genetic polymorphisms differently influencing the emergence of atrophy and fat accumulation in HIV-related lipodystrophy. AIDS 2008; 22:1769-1778.

30. Hodis HN and Mack WJ: Triglyceride-rich lipoproteins and the progression of coronary artery disease. Curr Opin Lipidol 1995;6:209-214.

31. Wang CS, McConathy WJ, Kloer HU, and Alaupovic P: Modulation of lipoprotein lipase activity by apolipoproteins. Effect of apolipoprotein C-III. J Clin Invest 1985;75:384-390.

32. Widen E, Lehto M, Kanninen T, Walston J, Shuldiner AR, and Groop LC: Association of a polymorphism in the beta 3adrenergic-receptor gene with features of the insulin resistance syndrome in Finns. N Engl J Med 1995;333:348-351.

33. Clement K, Vaisse C, Manning BS, et al.: Genetic variation in the beta 3-adrenergic receptor and an increased capacity to gain weight in patients with morbid obesity. N Engl J Med 1995;333:352-354.

34. Nasi M, Pinti M, Bugarini R, et al.: Genetic polymorphisms of Fas (CD95) and Fas ligand (CD178) influence the rise in $\mathrm{CD} 4+\mathrm{T}$ cell count after antiretroviral therapy in drug-naive HIV-positive patients. Immunogenetics 2005;57:628-635.

35. Blanco F and Carr A: Lipodystrophy syndrome: Diagnostic, clinic and therapeutic aspects. AIDS Rev 2001;3:98-105.

36. Likanonsakul S, Rattanatham T, Feangvad S, et al.: HLA$\mathrm{CW}^{*} 04$ allele associated with nevirapine-induced rash in HIV-infected Thai patients. AIDS Res Ther 2009;6:22.

37. Ueda M, Hung $Y C$, Terai $Y$, et al.: Fas gene promoter -670 polymorphism $(\mathrm{A} / \mathrm{G})$ is associated with cervical carcinogenesis. Gynecol Oncol 2005;98:129-133.

38. Walker UA, Bickel M, Lutke Volksbeck SI, et al.: Evidence of nucleoside analogue reverse transcriptase inhibitorassociated genetic and structural defects of mitochondria in adipose tissue of HIV-infected patients. J Acquir Immune Defic Syndr 2002;29:117-121.

39. Gallant JE, Staszewski S, Pozniak AL, et al.: Efficacy and safety of tenofovir DF vs stavudine in combination therapy in antiretroviral-naive patients: A 3-year randomized trial. JAMA 2004;292:191-201.

40. Sievers M, Walker UA, Sevastianova K, et al.: Gene expression and immunohistochemistry in adipose tissue of HIV type 1-infected patients with nucleoside analogue reversetranscriptase inhibitor-associated lipoatrophy. J Infect Dis 2009;200:252-262.

41. Kanemitsu S, Ihara K, Saifddin A, et al.: A functional polymorphism in fas (CD95/APO-1) gene promoter associated with systemic lupus erythematosus. J Rheumatol 2002;29: 1183-1188.

42. Huang QR, Danis V, Lassere M, Edmonds J, and Manolios $\mathrm{N}$ : Evaluation of a new Apo-1/Fas promoter polymorphism in rheumatoid arthritis and systemic lupus erythematosus patients. Rheumatology (Oxford) 1999;38:645-651.

43. van Veen T, Kalkers NF, Crusius JB, et al.: The FAS-670 polymorphism influences susceptibility to multiple sclerosis. J Neuroimmunol 2002;128:95-100.

44. Oksanen L, Mustajoki P, Kaprio J, et al.: Polymorphism of the beta 3-adrenergic receptor gene in morbid obesity. Int J Obes Relat Metab Disord 1996;20:1055-1061.

45. de Silva AM, Walder KR, Boyko EJ, et al.: Genetic variation and obesity in Australian women: A prospective study. Obes Res 2001;9:733-740.

46. Garenc C, Perusse L, Rankinen T, et al.: The Trp64Arg polymorphism of the beta3-adrenergic receptor gene is not associated with training-induced changes in body composition: The HERITAGE Family Study. Obes Res 2001;9:337-341.

47. Pollex RL, Ban MR, Young TK, et al.: Association between the $-455 \mathrm{~T}>\mathrm{C}$ promoter polymorphism of the APOC3 gene and the metabolic syndrome in a multi-ethnic sample. BMC Med Genet 2007;8:80.

48. Bonnet E, Bernard J, Fauvel J, Massip P, Ruidavets JB, and Perret B: Association of APOC3 polymorphisms with both dyslipidemia and lipoatrophy in HAART-receiving patients. AIDS Res Hum Retroviruses 2008;24:169-171.

49. Bonnet E, Genoux A, Bernard J, Fauvel J, Massip P, and Perret B: Impact of genetic polymorphisms on the risk of lipid disorders in patients on anti-HIV therapy. Clin Chem Lab Med 2007;45:815-821.

50. Shohet RV, Vega GL, Bersot TP, et al.: Sources of variability in genetic association studies: Insights from the analysis of hepatic lipase (LIPC). Hum Mutat 2002;19:536-542.

51. Foulkes AS, Wohl DA, Frank I, et al.: Associations among race/ethnicity, ApoC-III genotypes, and lipids in HIV-1infected individuals on antiretroviral therapy. PLoS Med 2006;3:e52.

Address correspondence to: Sirirat Likanonsakul

Bamrasnaradura Infectious Diseases Institute Department of Disease Control Ministry of Public Health 126 Tiwanon Road Muang, Nonthaburi 11000 Thailand

E-mail: siratlik@gmail.com 